\title{
Disponibilização dos Nutrientes das Fezes de Bovinos em Pastejo para a Forragem
}

\author{
Sérgio Pereira Braz ${ }^{1}$, Domicio do Nascimento Junior ${ }^{2}$, Reinaldo Bertola Cantarutti ${ }^{3}$, \\ Adair José Regazzi ${ }^{4}$, Carlos Eugênio Martins ${ }^{5}$, Dilermando Miranda da Fonseca ${ }^{6}$
}

\begin{abstract}
RESUMO - Em local adjacente aos ensaios realizados por Braz et al. (2001) foi estabelecida outra área, com objetivo de avaliar a degradação das placas de fezes depositadas pelos bovinos e a influência dos nutrientes liberados na produção e nos teores de nutrientes da forragem. Foram coletadas 50 placas de fezes imediatamente após a excreção pelo animal e mantidas no campo sob incubação por períodos de 7, 14, 28, 56 e 112 dias. Foi verificada contínua e intensa variação nos teores de potássio das placas, que passaram de 0,25 para $0,05 \%$ após os 112 dias; neste período, a liberação do nutriente da placa correspondeu a 90\% da quantidade inicial. Os teores de FDA apresentaram, na primeira semana, redução de 50\% do inicial, que provavelmente favoreceu a concentração das cinzas na placa, como observado. Não se observou variação dos teores de $\mathrm{N}$ e P, sendo que o desaparecimento ocorreu de forma restrita, apresentando a mesma tendência do desaparecimento de matéria seca, provavelmente em função da ação de agentes físicos, já que a atividade biológica nas placas foi baixa. Quanto à influência dos nutrientes liberados da placa na produção e teor de nutrientes da forragem, foram verificadas, após 112 dias de incubação, diferenças quanto à produção e aos teores de $\mathrm{K}$ na região central de avaliação, ou seja, num raio de até $25 \mathrm{~cm}$ do centro da placa, não foi verificada diferença quanto à produção ou aos teores dos nutrientes em outras regiões avaliadas.
\end{abstract}

Palavras-chave: fezes de bovinos, degradação, decomposição, mineralização, reciclagem, nutrientes

\section{Fecal Nutrients Liberation of Grazing Cattle to the Forage}

\begin{abstract}
In an area adjacent to trials conducted by Braz et al. (2001) another area was fenced to evaluate the degradation of piles feces liberated by the cattle and the influence of nutrients liberated to the forage on the nutrients production and concentrations. Fifty piles feces were collected immediately after excretion by the animal and maintained in the field for periods of $7,14,28,56$ and 112 days of incubation. It was observed a continuous and high variation in the potassium contents through feces, that ranged from .25 to $.05 \%$ after 112 days, in this period, the pile nutrient liberation corresponded to $90 \%$ initial amount. ADF contents, in the first week, decreased 50\% from the beginning, representing a later tendency for increase in the ADF fecal concentration, as previously observed. As for the concentrations of $\mathrm{N}$ and $\mathrm{P}$, it was observed that liberation was restricted and correlated with the degradation of dry matter, probably as a function of low biological activity in the feces and of consequent liberation of these nutrients in the particulate form. Concerning the influence of liberated nutrients through the feces to the forage on the nutrient production and concentration, there was a high variation in $\mathrm{K}$ concentration and production only in the central region of evaluation after 112 days of incubation, i.e., in a radium of $25 \mathrm{~cm}$ from the pile center, there was no difference in the nutrients production and concentrations in the other evaluated regions.
\end{abstract}

Key Words: sustainability, degradation of feces piles, nutrients incorporation

\section{Introdução}

No Brasil, predominam solos de baixa fertilidade e condições climáticas adversas, que afetam negativamente a qualidade das forrageiras, proporcionando, em muitos casos, limitações no consumo de nutrientes e o atendimento das exigências nutricionais dos animais, repercutindo diretamente nas baixas produtividades observadas.

Sob estas condições particulares dos sistemas de produção, tem sido pouco estudado o efeito do com- partimento animal sobre a reciclagem de nutrientes no ecossistema de pastagens. Os efeitos cumulativos das excreções nas propriedades dos solos sob pastagens não são bem descritos ainda, provavelmente pela dificuldade de separar estes efeitos de outras propriedades do sistema solo-planta-animal (Carran \& Theobald, 2000).

A lenta degradação do material fecal aparentemente resulta da baixa taxa de liberação dos nutrientes presentes em formas orgânicas (Haynes \& Williams, 1993). Assim, paralelamente à desintegração e

\footnotetext{
${ }^{1}$ Mestre em Zootecnia/UFV. E.mail: braz@ufrrj.br

2 Professor do DZO. Bolsista do CNPq. E.mail: domicion@ufv.br

3 Professor do Departamento de Solos/UFV. E.mail: cantarutti@solos.ufv.br

4 Professor do Departamento de Informática/UFV. E.mail: adairreg@ufv.br

${ }^{5}$ Pesquisador da EMBRAPA/Gado de Leite. E.mail: caeuma@cnpgl.embrapa.br

6 Professor do DZO. E.maiil: dfonseca@ufv.br
} 
lixiviação dos nutrientes presentes em formas solúveis, que culmina com o desaparecimento da placa, o aproveitamento de seus nutrientes pelas plantas dependerá da mineralização das formas orgânicas dos nutrientes a formas inorgânicas, que dependerá, por sua vez, da atividade da micro fauna, ou seja, principalmente dos fungos e bactérias.

Segundo Haynes \& Willians (1993), dois processos contribuem para degradação das placas de fezes e, dessa forma, a liberação dos nutrientes, que são (1) a quebra física, causada principalmente pelo impacto das gotas de chuva, e o pisoteio dos animais e (2) a degradação biológica, que é produzida pela biota como fungos, bactérias, besouros e minhocas.

Desse modo, a liberação dos nutrientes para as plantas dependerá tanto da porcentagem dos nutrientes prontamente disponíveis para lixiviação, como dos seus teores nas placas de fezes, de modo que se mostre um substrato adequado para favorecer a colonização e atividade microbiana e conseqüente mineralização; nesse sentido, destaca-se a importância, principalmente, das relações $\mathrm{C}: \mathrm{N}, \mathrm{C}: \mathrm{P}$ e das proporções dos nutrientes presentes em formas resistentes à mineralização, como aqueles associados aos constituintes da parede celular.

Diante disso, procurou-se avaliar a degradação das placas de fezes depositadas por bovinos e a influência dos nutrientes liberados na produção e teores de nutrientes da forragem, em uma pastagem de Brachiaria decumbens, em condições representativas da Zona da Mata de Minas Gerais.

\section{Material e Métodos}

O experimento foi conduzido no Campo Experimental de Coronel Pacheco pertencente à EMBRAPA Gado de Leite em Coronel Pacheco, na Zona da Mata de Minas Gerais (Lat. 21035 " S, Long. 430 15" W, Hp 0435,0 m).

Na Figura 1 estão representadas a precipitação pluviométrica diária em milímetros (mm) e a temperatura média mensal em ${ }^{\circ} \mathrm{C}$ verificadas durante o período experimental, que se estendeu de 8 de setembro a 28 de dezembro de 1999.

Numa área de pastagem de Brachiaria decumbens, sobre latossolo vermelho-amarelo, com declividade aproximada de $35^{\circ}$, foi cercada uma área impedindo a entrada de animais, toda a vegetação foi roçada no nível do solo, sendo então demarcados com estacas, 50 quadrantes com dimensão de 2,5x2,5 metros.

Em local adjacente, onde Braz et al. (2001) conduziram ensaio relacionado, foram coletadas 50 placas de fezes imediatamente após a defecação pelos animais e transferidas cuidadosamente para um suporte de tela de arame com malha de um $\mathrm{cm}$ e dimensão de $33 \times 33 \mathrm{~cm}$, procurando obedecer rigorosamente a forma e dimensão original.

Neste momento, uma pequena amostra do material foi colhida e armazenada num saco plástico e, ainda no campo, colocada em caixa térmica com gelo. Posteriormente, este material foi levado para o laboratório e conservado em câmara fria a $-4^{\circ} \mathrm{C}$ até a realização das análises químicas.

Na seqüência, o material já acondicionado sobre o suporte de tela foi pesado e finalmente colocado aleatoriamente nos quadrantes demarcados.

Ao $7^{\circ}, 14^{\circ}, 28^{\circ}, 56^{\circ}$ e $112^{\circ}$ dia, 10 placas foram colhidas, pesadas novamente e amostradas e, da mesma forma que as amostras colhidas inicialmente, foram levadas para o laboratório e conservadas em câmara fria a $-4^{\circ} \mathrm{C}$ até a realização das análises químicas.

Assim, cada uma das placas de fezes tinha duas amostras, uma colhida no tempo inicial e a outra após o referido tempo de amostragem.

Ao final dos 112 dias, mediu-se a influência dos nutrientes das placas de fezes na produção e no teor de nutrientes de forragem. Para isso, estabelecendo como referência o centro das dez placas, foram

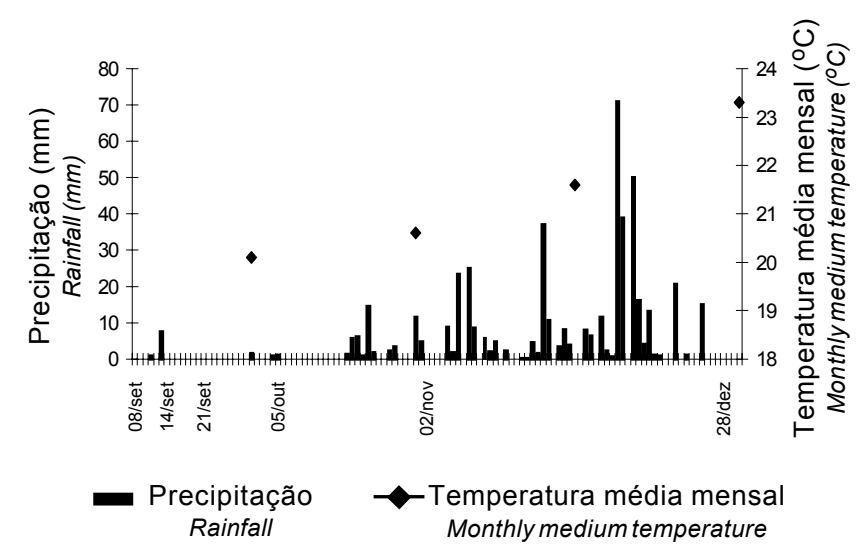

Figura 1 - Precipitação pluviométrica diária $(\mathrm{mm})$ e temperatura média mensal $\left({ }^{\circ} \mathrm{C}\right)$ durante os períodos experimentais do ensaio realizado.

Figure 1 - Daily rainfall and monthly average temperature $\left({ }^{\circ} \mathrm{C}\right)$, during the experimental periods. 
coletadas cinco amostras da forragem disponível ao nível do solo. Uma delas foi coletada num círculo central com $25 \mathrm{~cm}$ de raio e as outras quatro, nas faixas radiais de 25 a $50 \mathrm{~cm}$ e de 50 a $100 \mathrm{~cm}$ do centro da placa. Admitindo um eixo transversal ao declive do terreno, a forragem produzida na parte inferior do relevo numa angulação de 180 graus foi separada da produzida na parte superior. Para auxiliar este processo, foi construída um molde de vergalhão de ferro, favorecendo a padronização da amostragem nos 10 pontos.

Após a pesagem das cinco amostras de forragem colhidas em cada uma das 10 placas de fezes, foram colhidas subamostras do material para secagem em estufa de ventilação forçada por 72 horas a $60^{\circ} \mathrm{C}$, sendo processadas em moinho tipo "Willey" e armazenadas em frascos de vidro até a análise laboratorial.

As amostras de fezes foram retiradas da câmara fria e, antes de descongelar completamente, foram homogeneizadas em almofariz, sendo que parte foi acondicionada em frasco de vidro e mantida em refrigeração a $-4^{\circ} \mathrm{C}$ e outra parte foi colocada rapidamente para secar em estufa de ventilação forçada por 72 horas a $60^{\circ} \mathrm{C}$, obtendo-se os pesos antes e depois da secagem, sendo posteriormente processadas em moinho tipo "Willey" e armazenadas em frascos de vidro até a análise laboratorial.

As amostras mantidas sob refrigeração foram utilizadas para determinação dos teores de nitrogênio total, nitrato e amônio. Para determinação dos teores de nitrogênio total, procedeu-se à digestão sulfúrica do material e, posteriormente, à destilação pelo método semimacro KJELDAHL (Silva, 1990).

Os teores de nitrato e amônio foram determinados após a extração em água com agitação por 15 minutos e decantação por 16 horas, sendo utilizado o sobrenadante para as determinações, de acordo com metodologia descrita por Tedesco et al. (1985), utilizando destilador semimacro KJELDAHL, e redução do nitrato a amônio pela utilização da liga de devarda.

Nas amostras de fezes submetidas à pré-secagem, bem como as de forragem, foram determinados os teores de matéria seca, os minerais fósforo e potássio e o teor de cinzas e FDA.

A matéria seca foi determinada por diferença de peso após secagem em estufa a $105^{\circ} \mathrm{C}$ (Silva, 1990).

As amostras foram submetidas à digestão nitroperclórica para diferenciação dos teores de P e
K. O P foi determinado colorimetricamente (Silva, 1990), o K por espectrofotometria de chama.

Finalmente, os teores de cinzas e FDA foram determinados por metodologia descrita por Silva (1990).

Procedeu-se à análise de regressão para o estudo da variação do desaparecimento dos nutrientes das placas, em função dos períodos de amostragem. Para tanto, considerou-se como variáveis dependentes o desaparecimento dos constituintes (matéria seca (MS), nitrogênio, fósforo, potássio, cinzas e FDA) e como variável independente, os períodos de amostragem $(7,14,28,56$ e 112 dias), tendo sido adotado o modelo do delineamento inteiramente ao acaso com 10 repetições. O cálculo para determinação do desaparecimento dos constituintes foi obtido pela diferença entre as quantidades iniciais e finais destes nas placas, expressa como porcentagem do conteúdo inicial na placa.

Para o estudo da influência dos nutrientes liberados das placas de fezes na produção e no teor de nutrientes da forragem, foi adotado o modelo do delineamento inteiramente ao acaso com cinco tratamentos e 10 repetições, sendo que os tratamentos foram:

$\mathrm{T} 1=$ forragem colhida em um raio de $25 \mathrm{~cm}$ do centro da placa

$\mathrm{T} 2=$ forragem colhida na faixa de 25 a $50 \mathrm{~cm}$ na face superior do relevo

$\mathrm{T} 3$ = forragem colhida na faixa de $50 \mathrm{a} 100 \mathrm{~cm}$ na face superior do relevo

$\mathrm{T} 4$ = forragem colhida na faixa de 25 a $50 \mathrm{~cm} \mathrm{na}$ face inferior do relevo

$\mathrm{T} 5=$ forragem colhida na faixa de $50 \mathrm{a} 100 \mathrm{~cm}$ na face inferior do relevo

Os tratamentos foram comparados pelo teste $\mathrm{F}$, utilizando-se o método dos contrastes ortogonais, cujo esquema da análise de variância está apresentado na Tabela 1.

Para a análise da variação dos teores de umidade nas placas, juntamente com a variação da precipitação, dos teores dos constituintes das placas (nitrogênio, fósforo, potássio, cinzas e FDA) durante as amostragens aos 7, 14, 28, 56 e 112 dias, e dos teores de nitrogênio total, nitrato e amônio e da proporção de nitrato + amônio (nitrogênio inorgânico), em relação ao nitrogênio total, utilizou-se estatística descritiva, sendo os dados representados graficamente. 
Tabela 1 - Esquema da análise de variância dos dados referentes à influência dos nutrientes liberados das placas de fezes na produção e teor de nutrientes da forragem

Table 1 - Scheme of analysis of variance of data concerning the influence of the nutrients liberated through feces piles on the forage nutrient production and content

\begin{tabular}{llc}
\hline FV & & GL \\
$S V$ & & DF \\
\hline $\begin{array}{ll}\text { Tratamentos } \\
\text { Treatments }\end{array}$ & $(4)$ \\
\hline & & \\
& Contrastes & \\
& Contrasts & 1 \\
& Y1 (T1 vs T2+T3+T4+T5) & 1 \\
& Y2(T2+T3 vs T4+T5) & 1 \\
& Y3 (T2 vs T3) & 1 \\
Total & Y4(T4 vs T5) & 49 \\
Total & & \\
\hline
\end{tabular}

\section{Resultados e Discussão}

Na Figura 2 estão apresentadas a precipitação pluviométrica diária durante o período experimental, no período de 8 de setembro a 28 de dezembro de 1999 e a variação da umidade das placas de fezes nos períodos de amostragem, aos 7, 14, 28, 56 e 112 dias de incubação no campo, pode ser observado que a escassez das chuvas no período que antecedeu as amostragens iniciais, aos 7, 14 e 28 dias, pode ter favorecido a secagem das placas.

Entretanto, em um período de 56 dias entre as amostragens aos 56 e 112 dias, foi observada a ocorrência de chuvas em 33 dias, favorecendo a manutenção de elevados teores de umidade nas placas de fezes, ao contrário do período antecedente. Estas, inicialmente, apresentavam cerca de $75 \%$ de umidade, tendo estes valores decrescido para próximo de $30 \%$ aos sete dias e, posteriormente, para $20 \%$ aos 14 e 28 dias. Cabe destacar que aos 112 dias as placas de fezes apresentaram baixo teor de umidade, provavelmente devido ao fato de que, nos quatro dias antecedentes à amostragem, não ocorreram chuvas.

Assim, na amostragem das placas, aos sete dias, foi observada a formação de uma "crosta" sobre a superfície das placas, em função da secagem do material na camada mais externa, mas a parte interior apresentavase ainda com certa umidade, permitindo a atividade e presença de besouros coprófagos ("rola bosta").

Nas amostragens aos 14 e 28 dias, observou-se que todo o volume das placas estava seco de forma homogênea, não sendo observada atividade ou presença de insetos, minhocas ou outros organismos visíveis a olho nu que pudessem favorecer a degradação das placas. Aos 56 dias, apesar de as placas terem apresentado elevado teor de umidade (acima de $40 \%$ ), também não foi observada a atividade ou presença de qualquer organismo, visível a olho nu, o que se repetiu na última amostragem aos 112 dias.

Na Figura 3 está representada a variação dos teores denitrogênio, fósforo, potássio, cinzas eFDA nas placas durante as amostragens. Os teores de fósforo e nitrogênio não apresentaram variações expressivas durante as amostragens, entretanto, foi observada acentuada redução nos teores de potássio das placas até a última avaliação, em que os teores passaram inicialmente de próximo de $0,25 \%$ para menos que $0,05 \%$ aos 112 dias.

Pode-se observar também na Figura 3 a tendência de aumento nos teores de cinzas nas placas ao longo das amostragens, enquanto os teores de FDA, após rápida queda na primeira semana, passaram de $80 \%$ para próximo de $40 \%$, apresentaram tendência a aumento, chegando ao final dos 112 dias com teores próximos de $50 \%$.

A intensa redução dos teores de FDA na primeira amostragem pode estar relacionada à atividade microbiológica nas placas. Este fato pode ser confirmado pela análise da Figura 4, na qual estão representadas as variações no desaparecimento dos constituintes das placas (matéria seca, nitrogênio, fósforo, potássio, cinzas e FDA), como porcentagem das quantidades presentes inicialmente.

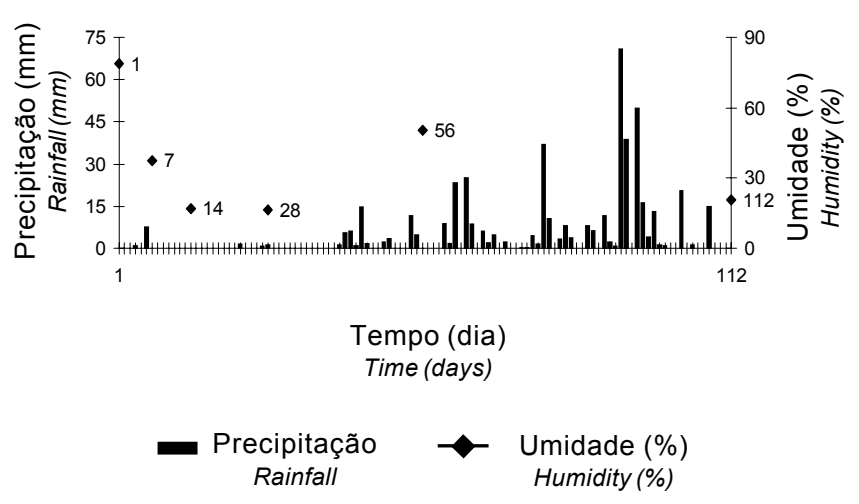

Figura 2 - Precipitação pluviométrica e variação da umidade das placas de fezes entre os períodos de amostragem aos 7, 14, 28, 56 e 112 dias do período experimental.

Figure 2 - Rainfall data and humidity variation of feces piles among the for sampling periods of 7, 14, 28, 56 and 112 days of experimental period. 
Assim, pode-se observar que as perdas nas quantidades de FDA (Figura 4) acima de $40 \%$, ocorridas já aos 7 dias, ocorreram em paralelo com aumento proporcional de próximo de $10 \%$ das quantidades de cinzas nas placas, enquanto todos os outros constituintes mantiveram-se praticamente inalterados. Pode-se atribuir este fato ao consumo de FDA pelos microorganismos e conseqüente liberação de $\mathrm{CO}_{2}$, favorecendo a concentração de cinzas nas placas.
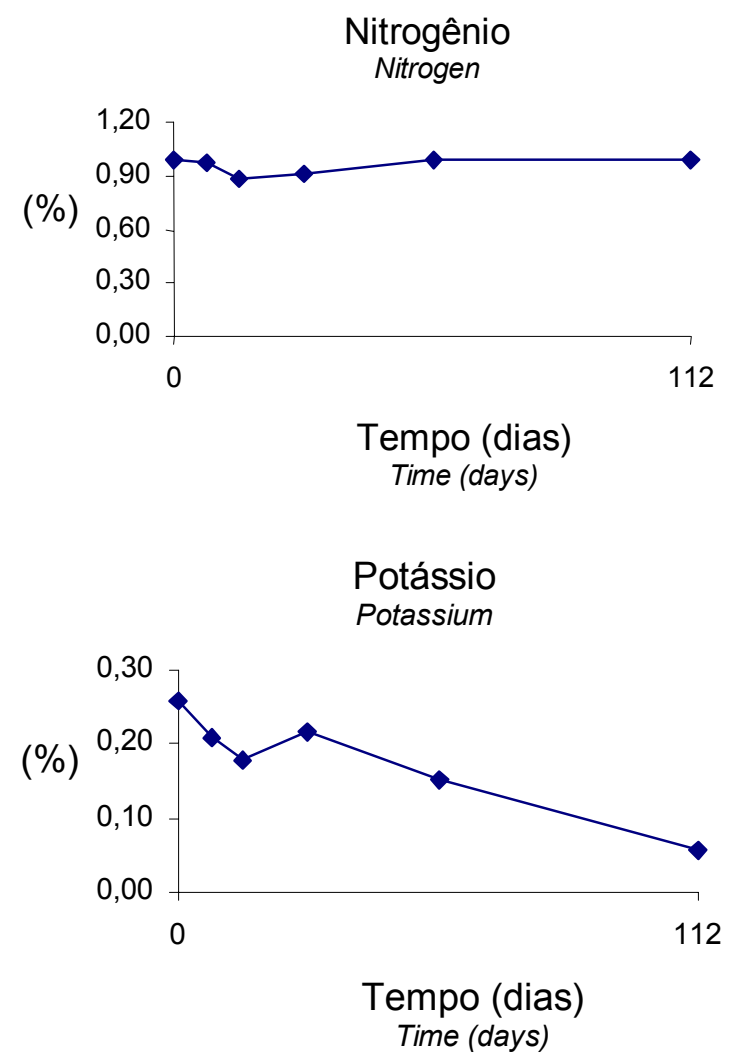

Macdiarmid \& Watkin (1972ab), em estudo semelhante, obtiveram resultado contrastante quanto à variação dos teores de FDA, verificando aumentos nos teores de FDA, que inicialmente eram próximos de $23 \%$ e passaram para próximo de $29 \%$ aos 20 dias de estudo, mantendo-se praticamente inalterados até os 55 dias.

A queda dos teores de potássio (Figura 3) concordou com o desaparecimento do nutriente na placa, sendo que na última amostragem, aos 112 dias, o

(\%)

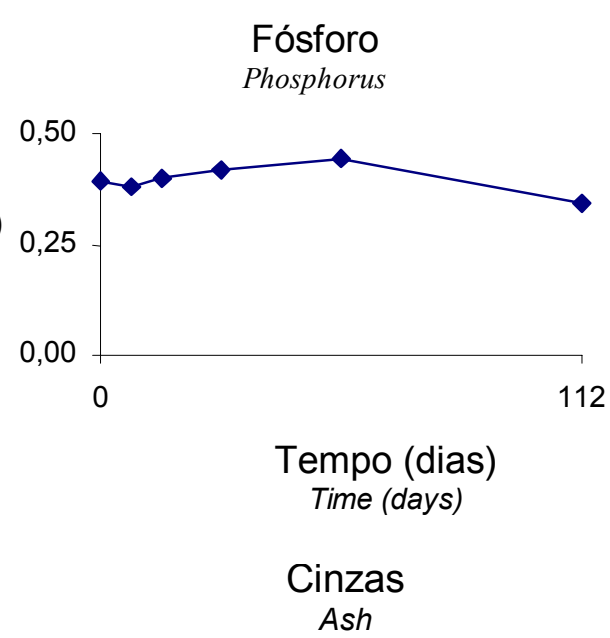

(\%)

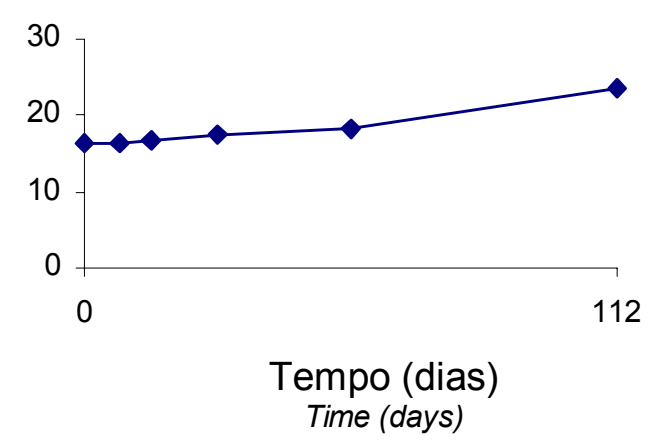

FDA

$A D F$

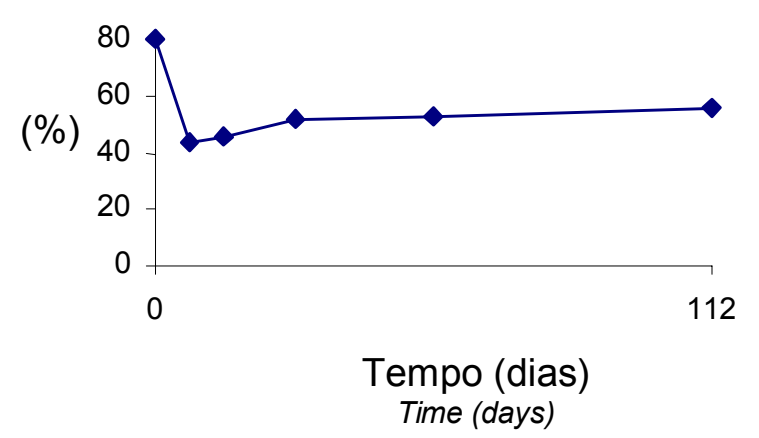

Figura 3 - Variação dos teores de nitrogênio, fósforo, potássio, cinzas e FDA, em \% de matéria seca, entre as amostragens das placas de fezes, durante os 112 dias do período experimental.

Figure 3 - Variation of nitrogen, phosphorus, potassium, ash and ADF contents, in \% dry mater, among feces piles samples for 112 days of experimental period. 
desaparecimento correspondeu a próximo de $90 \%$ das quantidades presentes inicialmente (Figura 4).

Weeda (1967) verificou que a liberação de potássio das placas de fezes é rápida, ocorrendo o pico dos teores do nutriente no solo um mês após a aplicação das placas. Davies (1962), citado por Haynes \& Willians (1993), reportou que praticamente todo potássio das fezes de bovinos é solúvel em água, o que favorece sua lixiviação e liberação das placas.

O processo de desintegração das placas, ou seja, o desaparecimento de matéria seca ocorreu de forma restrita, já que se observou precipitação de $478 \mathrm{~mm}$ no período do estudo e, dos 112 dias do período de avaliação, em 48 destes, foi observada a ocorrência de chuvas, o que poderia ter favorecido o processo de desintegração física das placas, proporcionado pelo impacto das gotas de chuva, que é descrito por Haynes \& Willians (1993), juntamente com a atividade microbiológica, como principal fator responsável pela desintegração ou decomposição das placas, entretanto, menos que $40 \%$ da matéria seca das placas desapareceu durante os 112 dias de estudo.

Na Nova Zelândia, Rowart et al. (1985) verificaram diferenças quanto ao tempo para a completa decomposição das placas de fezes, sendo que no inverno foram gastos 28 dias, enquanto no verão

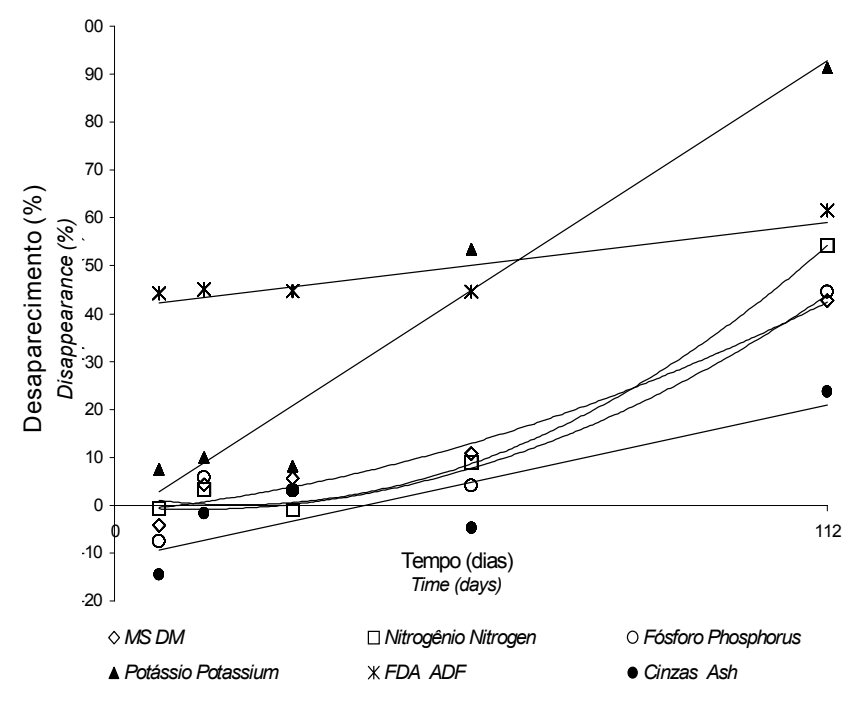

Figura 4 - Desaparecimento (\%) de matéria seca (MS), nitrogênio, fósforo, potássio, cinzas e FDA entre as amostragens aos 7, 14, 28, 56 e 112 dias do período experimental.

Figure 4 - Disappearance(\%)of dry matter (DM) nitrogen, phosphorus, potassium, ash and ADF losses (\%) among feces piles samples for 7, 14, 28, 56 and 112 days of experimental period. foram necessários 78 dias para a completa decomposição das placas. Em região árida da Austrália, Bromfield \& Jones (1970) verificaram a ocorrência de $40 \%$ de perda de peso de amostras de fezes em um período de dois anos. Rixon \& Zorin (1978) verificaram que, após 20 meses de incubação, entre 50 e $62 \%$ das amostras de fezes persistiram à degradação e concluíram que a regular adição de umidade por irrigação não resultou em aumentos da taxa de desaparecimento do material fecal.

A redução dos teores de umidade das placas, no período inicial até os 28 dias pode ter afetado o processo desintegração física das placas nos períodos subseqüentes. Assim, a formação de uma "crosta" seca sobre a superfície das placas e, posteriormente, a intensa secagem podem ter induzido transformações químicas nas placas, que, mesmo após a reidratação pela água das chuvas, não foram sensíveis ao impacto das próprias gotas, que representam importante mecanismo para desintegração das placas.

Weeda (1967) verificou que a taxa de desaparecimento das placas de fezes foi intensamente influenciada pelas condições ambientais. Assim, quando as condições favoreceram o ressecamento da camada superficial das placas de fezes, formando uma "crosta" dura sobre a superfície da placa, a erodibilidade era dificultada, por impedir a penetração de água, ocorrendo o retardamento do processo de decomposição.

Considerando-se que a decomposição da placa de fezes pode se dar pela oxidação do carbono e conseqüente mineralização e pela desintegração da placa por agentes físicos, na Figura 4 e Tabela 2, que representam o desaparecimento dos nutrientes da placas, pode-se observar que as tendências de desaparecimento das quantidades de matéria seca, nitrogênio e fósforo apresentam curvas semelhantes, levando a supor que o desaparecimento destes componentes esteja relacionado com sua liberação da placa por agente físico, independentemente da mineralização e lixiviação da placa, ou seja, sua liberação da placa se dá na própria forma orgânica. Comparando-se este resultado com o observado para o potássio, em que a proporção das quantidades desaparecidas excedeu aquela relacionada às próprias quantidades de matéria seca desaparecida, nota-se a possível existência de outro mecanismo de transporte de potássio das placas, provavelmente relacionado à lavagem das placas ou à lixiviação, que não foi significativo tanto para o nitrogênio como para o fósforo.

R. Bras. Zootec., v.31, n.4, p.1614-1623, 2002 
Tabela 2 - Equações ajustadas para as variáveis medidas em função dos dias de amostragem Table 2 - Fitted equations for the variables evaluated in function of sampling days

\begin{tabular}{|c|c|c|}
\hline $\begin{array}{l}\text { Variável(Y) } \\
\text { Variable }\end{array}$ & $\begin{array}{l}\text { Equação ajustada } \\
\text { Fitted equation }\end{array}$ & $\mathrm{R}^{2}$ \\
\hline $\begin{array}{l}\text { Matéria seca (MS) } \\
\text { Dry matter (DM) }\end{array}$ & $\hat{\mathrm{Y}}=-1,4863+0,1225 * * \mathrm{X}+0,0024 *: \mathrm{X}^{2}$ & 0,9740 \\
\hline $\begin{array}{l}\text { Nitrogênio } \\
\text { Nitrogen }\end{array}$ & $\hat{\mathrm{Y}}=2,3451-0,2392 * * \mathrm{X}+0,0063 * * \mathrm{X}^{2}$ & 0,9928 \\
\hline $\begin{array}{l}\text { Fósforo } \\
\text { Phosphorus }\end{array}$ & $\hat{Y}=-0,2068-0,1125^{* *} \mathrm{X}+0,0045^{* *} \mathrm{X}^{2}$ & 0,9296 \\
\hline $\begin{array}{l}\text { Potássio } \\
\text { Potassium }\end{array}$ & $\hat{Y}=-3,1576+0,8572 * * X$ & 0,9540 \\
\hline $\begin{array}{l}\text { Cinzas } \\
\text { Ash }\end{array}$ & $\hat{\mathrm{Y}}=-11,3270+0,2875 * * \mathrm{X}$ & 0,7557 \\
\hline $\begin{array}{l}\text { FDA } \\
A D F\end{array}$ & $\hat{Y}=41,1431+0,1593 * * X$ & 0,8101 \\
\hline
\end{tabular}

A liberação dos nutrientes por lavagem ou lixiviação das placas está condicionada à presença de formas inorgânicas dos nutrientes nas placas, sendo que tem sido considerado que o potássio presente nas fezes pode não estar relacionado a complexos orgânicos e, então, apresenta-se prontamente susceptível a esta via de liberação, diferentemente do nitrogênio e fósforo, os quais dependem da mineralização, que, por sua vez, depende da atividade microbiológica na placa para a conversão nas suas formas inorgânicas. Pode-se então atribuir a discrepância entre as quantidades liberadas de potássio e as de nitrogênio e fósforo à baixa atividade biológica na placa, uma vez que, provavelmente, o nitrogênio e fósforo não se apresentaram susceptíveis à liberação por lavagem ou lixiviação como observado para o potássio.

Na Figura 5 estão apresentadas a variação dos teores de nitrogênio total, amônio e nitrato e a porcentagem do nitrogênio inorgânico (amônio + nitrato) em relação ao nitrogênio total, nas placas de fezes.

Foi observado que as placas não apresentaram quantidades identificáveis de nitrato, sendo o nitrogênio inorgânico representado exclusivamente pelas quantidades de amônio presentes, que, de modo geral, foram muito baixas. No início do período de avaliação, o nitrogênio inorgânico representou próximo de $3 \%$ do nitrogênio total, entretanto, nas amostragens subseqüentes, o nitrogênio inorgânico passou a representar menos que $1 \%$ do total.

A maior proporção dos teores de amônia observada inicialmente (Figura 5) provavelmente está relacionada à liberação de metabólitos do próprio ani- mal e apresentou queda observada na primeira amostragem, provavelmente devido à susceptibilidade das perdas gasosas relacionadas com o gás amônio, já que a possível lavagem ou lixiviação para o solo pode ter sido restrita, face à quantidade de chuva ocorrida no período.

Os baixos valores observados (Figura 5) para as proporções dos teores das formas inorgânicas de nitrogênio em relação ao total, após a primeira amostragem, podem estar relacionados às ligações químicas envolvendo a fração orgânica, já que este material foi submetido ao processo de digestão pelo animal, sendo esperado que as formas mais lábeis fossem retidas pelo animal, e o nitrogênio indigestível presente nas fezes estivesse relacionado a componentes estruturais de difícil degradação, restringindo a atividade microbiana na placa.

Normalmente, resíduos orgânicos que apresentam menos que $2 \%$ de nitrogênio podem ser considerados de baixa qualidade e caracterizam-se pela lenta liberação de seus nutrientes, ou pela imobilização de nutrientes durante estágio anterior à decomposição. (Myers et al., 1994).

Haynes \& Williams (1993) consideram que a quantidade de nitrogênio mineralizado das fezes está intimamente relacionada com o conteúdo total. Os autores sugerem ainda que a mineralização do nitrogênio pode ser mais lenta nas fezes que nos materiais das plantas de que foi derivada, o que pode não ser somente devido à relação $\mathrm{C} / \mathrm{N}$, uma vez que esta pode ser semelhante entre os dois materiais, mas sim à larga proporção do carbono presente nas fezes como material fibroso e indigestível(celulose, hemicelulose e lignina). 


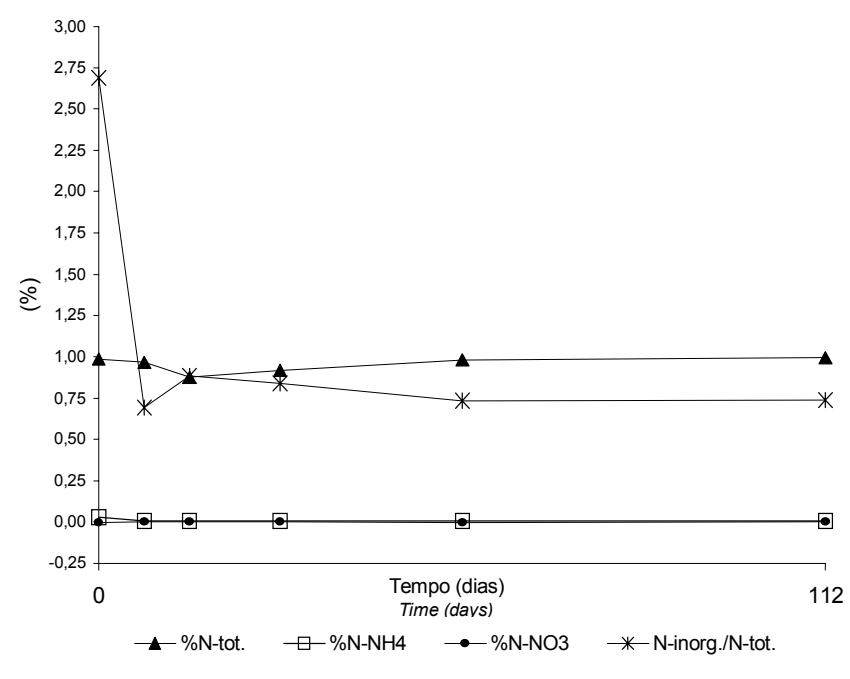

Figura 5 - Variação dos teores de nitrogênio total $(\mathrm{N}$ tot.), amônio $\left(\mathrm{N}-\mathrm{NH}_{4}\right)$, nitrato $\left(\mathrm{N}-\mathrm{NO}_{3}\right)$ e da porcentagem do nitrogênio inorgânico $\left(\mathrm{N}-\mathrm{NH}_{4}\right.$ $+\mathrm{N}-\mathrm{NO}_{3}$ ) em relação ao total (N-tot.), ( $\mathrm{N}$ inorg./ $\mathrm{N}$-tot.), entre as amostragens aos 7 , $14,28,56$ e 112 dias do período experimental.

Figure 5 - Variation of total nitrogen ( $N$-tot.), ammonio ( $N$ $\left.\mathrm{NH}_{4}\right)$ and nitrate $\left(\mathrm{N}-\mathrm{NO}_{3}\right)$ contents and of inorganic nitrogen percentage $\left(\mathrm{N}-\mathrm{NH}_{4}+\mathrm{N}-\mathrm{NO}_{3}\right)$ in relation to total $\mathrm{N}$ (N-tot.), (N-inorg./N-tot.), among sampling at $7,14,28,56$ and 112 days of experimental period.

Assim, pode-se considerar que a falta de umidade pode ter restringido a atividade biológica na placa somente no período inicial das amostragens, uma vez que, após os 56 dias, como já discutido, provavelmente as placas mantiveram-se com umidade suficiente para não restringir a atividade biológica, devendo estes fatos estarem relacionados à restrições químicas envolvendo os nutrientes na placa.

Quanto à liberação do fósforo, devido às semelhanças nas proporções liberadas e nas próprias características do nutriente com o nitrogênio, pode-se esperar o efeito dos mesmos fatores supostos para a restrição da liberação do nitrogênio, ou seja, após o processo de digestão do animal, foram consumidas as formas lábeis do nutriente, restando somente aquelas resistentes à decomposição, que levaria maior tempo para mineralização, tornando a liberação do fósforo restrita e favorecendo provavelmente o predomínio de mecanismos físicos relacionados com a liberação na própria forma orgânica.

Bromfield \& Jones (1970) mostraram que a quantidade de fósforo lixiviada depende mais da lavagem do material que do intervalo de tempo de incubação, sendo que a quantidade de fósforo lixiviada decresceu com as sucessivas extrações. Isto demonstra a importância da presença das formas inorgânicas para liberação do nutriente das placas, entretanto, os autores verificaram que, em condições de campo, em um período de dois anos, a concentração de fósforo total das amostras de fezes decresceu $60 \%$, indicando a dificuldade para a completa mineralização do nutriente.

$\mathrm{Na}$ Tabela 3 estão apresentadas as médias dos teores dos nutrientes e da produção da forragem colhida em um raio de $25 \mathrm{~cm}$ e nas faixas de 25 a $50 \mathrm{~cm}$ e de 50 a $100 \mathrm{~cm}$ na face superior e inferior do relevo em relação ao centro de 10 placas de fezes, sob incubação no campo por 112 dias. Na Tabela 4 está apresentado o resumo da análise de variância para os dados destas variáveis, assim como o teste para os contrastes inicialmente formulados.

Pode-se observar pela análise das Tabelas 3 e 4 que as placas de fezes influenciaram somente o aumento dos teores de potássio e a produção de matéria seca em um raio de $25 \mathrm{~cm}$ das placas de fezes estudadas, não sendo observada diferença quanto ao teor de nutrientes ou à produção de matéria seca entre as outras regiões estudadas.

O aumento dos teores de potássio na forragem apresentou concordância com as taxas de liberação do nutriente das placas, discutidas anteriormente.

Quanto às diferenças entre a produção de matéria seca na região central e na periferia da placa, podem estar relacionados três fatores: a resposta ao aumento dos teores de potássio, a formação de um micro clima ao redor da placa, favorecendo, principalmente, as condições de umidade do solo, e ainda outros nutrientes liberados da placa também podem ter influenciado a maior produção, apesar de não terem sido observadas diferenças significativas entre aqueles analisados, provavelmente face ao efeito de diluição dos nutrientes, já que a colheita do material ocorreu aos 112 dias, quando as plantas já tinham ultrapassado o estádio vegetativo, sendo observada durante a amostragem a intensa produção de sementes. 
Tabela 3 - Variação das médias dos teores de nitrogênio, fósforo e potássio da forrageira, em porcentagem de matéria seca e da produção de matéria seca total (MS), num raio de $25 \mathrm{~cm}$ e em duas faixas radiais na face superior (sup.) e inferior (inf.) do relevo entre 25 e $50 \mathrm{~cm}$ e entre 50 e $100 \mathrm{~cm}$ do centro de 10 placas de fezes sob incubação no campo por 112 dias

Table 3 - Means variation of forage nitrogen, phosphorus and potassium contents, in percentage of dry matter and of total dry matter (DM) production and of total dry matter production, in a radium of $25 \mathrm{~cm}$ and in two radial ranges in the superior (sup.) and inferior (inf.) sides of relief, from 25 to $50 \mathrm{~cm}$ and from 50 to $100 \mathrm{~cm}$ from the center of 10 feces piles, under field incubation for 112 days

\begin{tabular}{|c|c|c|c|c|}
\hline $\begin{array}{l}\text { Local } \\
\text { Place }\end{array}$ & $\begin{array}{c}\text { Nitrogênio (\%) } \\
\text { Nitrogen (\%) }\end{array}$ & $\begin{array}{c}\text { Fósforo (\%) } \\
\text { Phosphorus }(\%)\end{array}$ & $\begin{array}{l}\text { Potássio (\%) } \\
\text { Potassium (\%) }\end{array}$ & $\begin{array}{l}\operatorname{MS}\left(\mathrm{g} / \mathrm{m}^{2}\right) \\
D M\left(g / m^{2}\right)\end{array}$ \\
\hline Centro & 0,97 & 0,07 & 1,26 & 238,96 \\
\hline $\begin{array}{l}\text { Center } \\
\text { Faixa } 25-50 \mathrm{~cm} \text { superior } \\
25-50 \mathrm{~cm} \text { above }\end{array}$ & 0,90 & 0,07 & 1,03 & 169,67 \\
\hline $\begin{array}{l}\text { Faixa } 25-50 \mathrm{~cm} \text { inferior } \\
25-50 \mathrm{~cm} \text { below }\end{array}$ & 1,01 & 0,07 & 1,09 & 149,65 \\
\hline $\begin{array}{l}\text { Faixa } 50-100 \mathrm{~cm} \text { superior } \\
50-100 \mathrm{~cm} \text { above }\end{array}$ & 1,00 & 0,07 & 0,96 & 125,99 \\
\hline $\begin{array}{l}\text { Faixa } 50-100 \mathrm{~cm} \text { inferior } \\
50-100 \mathrm{~cm} \text { below }\end{array}$ & 0,89 & 0,06 & 1,04 & 133,60 \\
\hline
\end{tabular}

Tabela 4 - Resumo da análise de variância dos dados referentes à influência das placas de fezes na produção e teor de nutrientes da forragem

Table 4 - Summary of analysis of variance concerning the influence of feces piles on the nutrients production and content in forage

\begin{tabular}{|c|c|c|c|c|c|c|}
\hline \multirow[t]{2}{*}{ FV } & & \multirow[t]{2}{*}{$\begin{array}{l}\mathrm{GL} \\
D F\end{array}$} & \multicolumn{4}{|c|}{$\begin{array}{l}\text { QM } \\
S M\end{array}$} \\
\hline & & & $\begin{array}{l}\text { Nitrogênio } \\
\text { Nitrogen }\end{array}$ & $\begin{array}{c}\text { Fósforo } \\
\text { Phosphorus }\end{array}$ & $\begin{array}{l}\text { Potássio } \\
\text { Potassium }\end{array}$ & $\begin{array}{l}\text { MS } \\
D M\end{array}$ \\
\hline \multirow[t]{7}{*}{$\begin{array}{l}\text { Tratamentos } \\
\text { Treatments }\end{array}$} & & (4) & $(0,0308)^{\mathrm{NS}}$ & $(0,0002)^{\mathrm{NS}}$ & $(0,1235)^{*}$ & $(20561,39)^{*}$ \\
\hline & $\begin{array}{l}\text { Contrastes } \\
\text { Contrasts }\end{array}$ & & & & & \\
\hline & $\begin{array}{l}\left.\mathrm{Y}^{1} \text { (centro vs. outros }\right) \\
\left.Y^{1} \text { (center vs. other }\right)\end{array}$ & 1 & $0,0026^{\mathrm{NS}}$ & $0,0007^{\mathrm{NS}}$ & $0,4128^{*}$ & $71032,50^{*}$ \\
\hline & $\begin{array}{l}\mathrm{Y}^{2} \text { (sup. vs. inf.) } \\
Y^{2} \text { (above vs. below) }\end{array}$ & 1 & $0,0000^{\mathrm{NS}}$ & $0,0001^{\mathrm{NS}}$ & $0,0467^{\mathrm{NS}}$ & $385,05^{\mathrm{NS}}$ \\
\hline & $\begin{array}{l}\mathrm{Y}^{3}(25-50 \text { sup. vs. } 25-50 \text { inf. }) \\
Y^{3}(25-50 \text { above vs } 25-50 \text { below })\end{array}$ & 1 & $0,0571^{\mathrm{NS}}$ & $0,0000^{\mathrm{NS}}$ & $0,0251^{\mathrm{NS}}$ & $9539,39^{\mathrm{NS}}$ \\
\hline & $\begin{array}{l}\mathrm{Y}^{4}(50-100 \text { sup. vs. } 50-100 \text { inf. }) \\
Y^{4}(50-100 \text { above vs. } 50-100 \text { below })\end{array}$ & 1 & $0,0635^{*}$ & $0,0001^{\mathrm{NS}}$ & $0,0095^{\mathrm{NS}}$ & $1288,61^{\mathrm{NS}}$ \\
\hline & $\begin{array}{l}\text { Resíduo } \\
\text { Error }\end{array}$ & 45 & 0,6956 & 0,0071 & 2,1134 & 196777,19 \\
\hline
\end{tabular}

ns $\mathrm{P}>0,05(p<.05)$.

\section{Conclusões}

No processo de degradação de placas de fezes e disponibilização dos nutrientes para as plantas, com baixa atividade biológica nas placas, somente o potássio é prontamente disponibilizado para as plantas.

O nitrogênio e o fósforo são liberados em quantidades restritas, devido à estreita relação das quantidades dos nutrientes desaparecidos com a desintegração das placas. A liberação do $\mathrm{N}$ e do $\mathrm{P}$ ocorre na forma particulada, dependendo ainda da mineralização para o aproveitamento pelas plantas.

$\mathrm{O}$ efeito de liberação de nutrientes das placas ocorre a mais longo prazo que o estudado, pois depende da mineralização das formas orgânicas liberadas, com redução das perdas dos nutrientes do sistema por lixiviação, volatilização ou adsorção aos colóides do solo, caracterizando uma sincronia com a demanda do sistema.

A produção e os teores de $\mathrm{K}$ da forragem são influenciados pela distancia da placa de fezes, com valores decrescentes a partir de $25 \mathrm{~cm}$ do centro da placa. 


\section{Literatura Citada}

BRAZ, S.P.; NASCIMENTO Jr., D.; CANTARUTTI, R.B. et al. The effect of sheep on the recycling of phosphorus in hayedoff pastures. Australian Journal of Agricultural Research, v.21, p.699-711, 1970 .

CARRAN, R.A.; THEOBALD, P.W. Effects of excreta return on properties of a grazed pasture soil. Nutrient Cycling in Agroecosystems, v.56, p.79-85, 2000.

HAYNES, R. J.; WILLIAMS, P. H.Nutrient cycling and fertility in the grazed pasture ecosystem. Advances in Agronomy, v.49, p.119-199, 1993.

MacDIARMID, B.N.; WATKIN, B.R. The cattle dung patch. 2. Effect of dung patch on the chemical status of the soil, and ammonia nitrogen losses from the patch. Journal of the British Grassland Society, v.27, p.43-48, 1972a.

MacDIARMID, B.N.; WATKIN, B.R. The cattle dung patch. 3. Distribution and rate of decay of dung patches and their influence on grazing behaviour. Journal of the British Grassland Society, v.27, p.48-54, 1972 b.

MYERS, R.J.K.; PALM, C.A.; CUEVAS, E. et al. The synchronization of nutrient mineralisation and plant nutrient demand. In: WOOMER, P.L.; SWIFT, M.J. (Eds.) The biological management of tropical soil fertility. New York: John \& Sons, 1994. p.81-116.
RIXON, A.J.; ZORIN, M. Transformations of nitrogen and phosphorus in sheep faeces located in salt-bush rangeland and on irrigated pasture. Soil Biology and Biochemistry, v.10, p.347-354, 1978.

ROWARTH, J.S.; GILLINGHAM, A.G., TILLMAN, R.W.et al. Release of phosphorus from sheep faeces on grazed, hill country pastures. New Zealand Journal of Agricultural Research, v.28, p.497-504, 1985.

SILVA, D.J. Análise de alimentos (métodos químicos e biológicos). 2.ed. Viçosa, MG: Universidade Federal de Viçosa, 1990. $156 \mathrm{p}$.

TEDESCO, M.J.; VOLKWEISS, S.J.; BOHNEN, H. Análises de solo, plantas e outros materiais. Porto Alegre: Universidade Federal do Rio Grande do Sul, 1985. 188p. (Boletim Técnico de Solos, 5).

WEEDA, W.C. The effect of cattle dung patches on pasture growth, botanical composition, and pasture utilization. New Zealand Journal of Agricultural Research, v.10, p.150-159, 1967.

Recebido em: 19/06/01

Aceito em: 13/05/02 